\title{
EDITORIAL
}

\section{Pathological Changes in Memory Processing}

The pathological dysfunctions of memory processes are numerous and can be attributed to various causes. It was not possible, within the limited scope of this issue, to present all of them. We have thus emphasized a few examples, appearing to us as being of particular importance or originality.

Memory disturbances can be produced by the action of deleterious drugs. Alcohol is one of them. Relating emotion to memory retrieval processes, Béracochéa underlines the importance of damage to mammillary bodies, in a mouse model of the alcoholic Korsakoff syndrome. Benzodiazepines are compounds well known to impair memory processes, especially during the acquisition phase of a memory task. Savic et al. analyze the two subunits of the benzodiazepine binding sites most likely to be involved in these actions-the a1 - and a5-subunits.

Alzheimer disease is another very important field in which animal models can allow analytical approaches to memory dysfunction. Mineur et al. describe some of these models, with a special emphasis on the genetic models that have been tested behaviorally. Messier and Teutenberg offer new and challenging insights on the role of brain insulin, insulin growth factor, and insulin-degrading enzyme in learning processes, which could explain some of the memory deficits found in Alzheimer's disease by changes in the brain metabolism of/sensitivity to insulin related compounds, which might, in turn, lead to the accumulation of $\beta$-amyloid.

Certain compounds can have a positive action on memory deficiencies. Such is erythropoietin (EPO), able to reduce both behavioral and cognitive symptoms of mechanical brain injuries. Mala et al. present here a striking example, with the improvement by EPO of place learning in a radial maze, in fimbria-fornix transected rats.

Finally, whereas most studies use rodents as laboratory animals, Lind and Moustgaard show the interesting use that can be made of minipigs to demonstrate an interaction of emotional reactivity and cognitive factors in influencing learning abilities.

\section{Daniel Béracochéa and Georges Chapouthier \\ Bordeaux and Paris, France \\ November 2005}



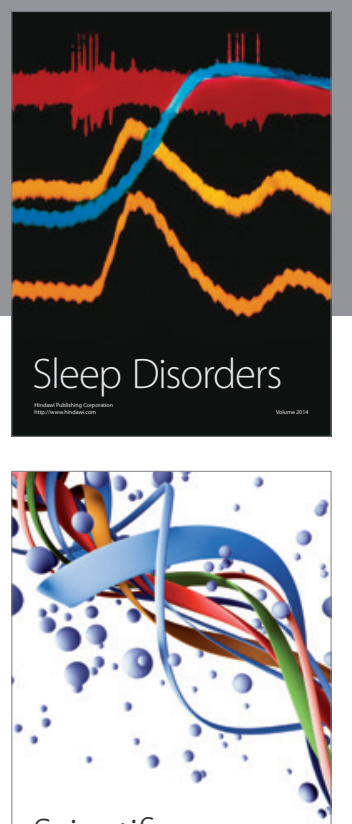

Scientifica
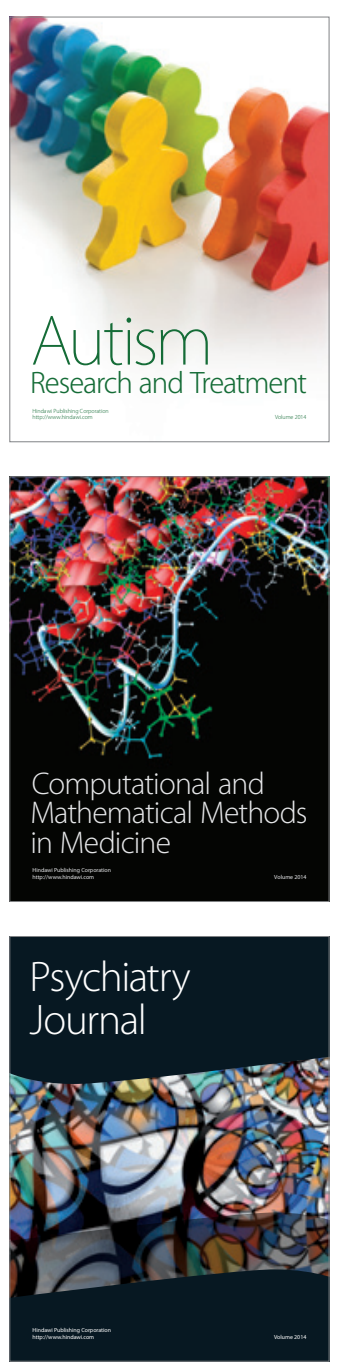
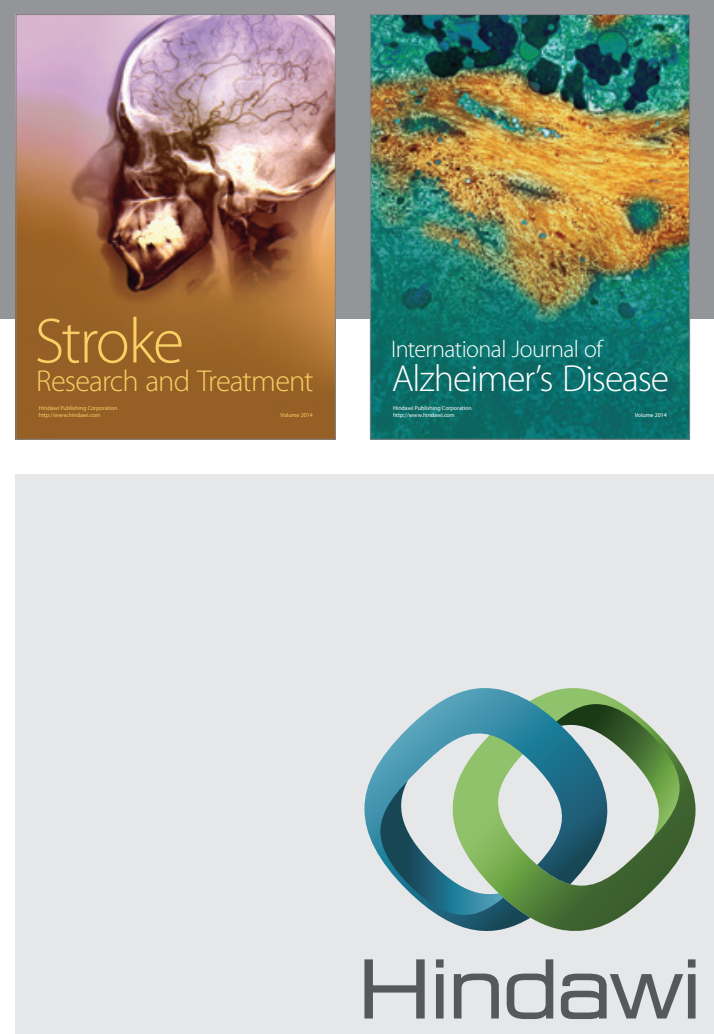

Submit your manuscripts at

http://www.hindawi.com
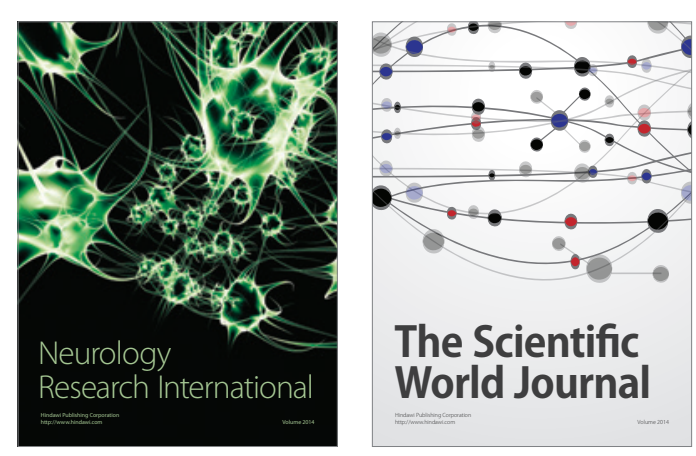

The Scientific World Journal

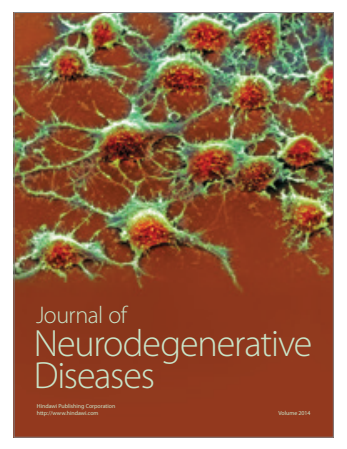

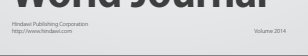

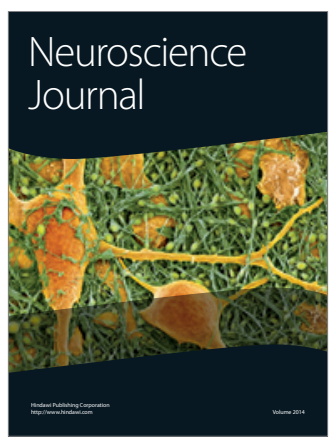

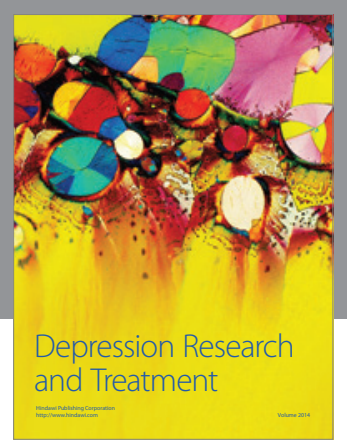
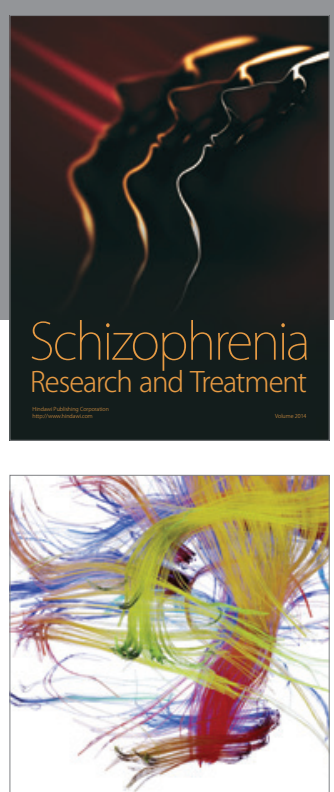

Brain Science

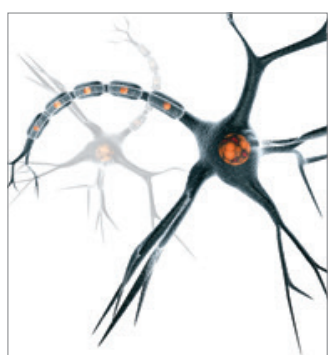

Neural Plasticity
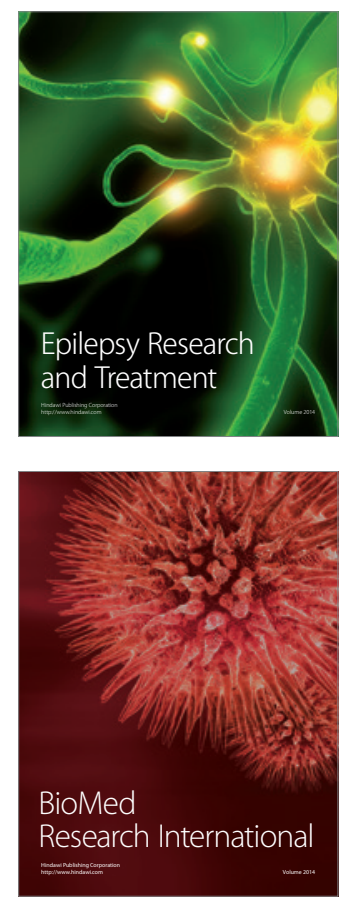

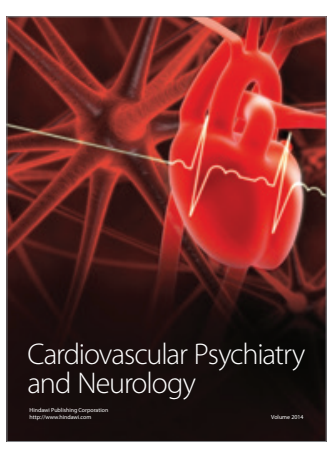

Parkinson's

Disease
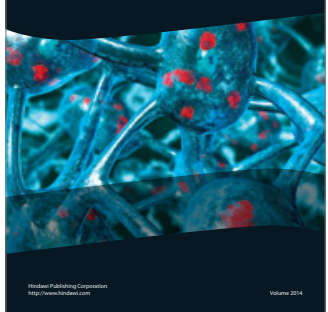